Population Redistribution and Economic Growth, United States, 1870-1950

1: Methodological Considerations and Reference Tables. By Everett S. Lee, Ann Ratner Miller, Carol P. Brainerd, and Richard A. Easterlin. Prepared under the direction of Simon Kuznets and Dorothy Swaine Thomas. (Memoirs of the American Philosophical Society, Vol. 45.) Pp. $x x+760$. (Philadelphia : American Philosophical Society, 1957.) $\tilde{5}$ dollars.

$\mathrm{T}$ HIS massive collection of data forms the first part of a larger study to be prepared under the direction of Profs. Kuznets and Thomas. As the title indicates, its primary function is methodological, and the provision of the basic data. Analysis and theoretical evaluation will have to await the appearance of the second volume in the series. Well over half the present volume consists of reference tables, and there is an explanatory text which shows in detail how the tables have been computed.

The tables treat four principal topics. For each of the 48 States and for the District of Columbia there are comparable series from 1870 to 1950 giving estimates of internal migration, figures relating to the labour force, estimates of manufacturing activity and State income estimates. The amount of detailed statistical work that has gone into the preparation of these figures must have been enormous, and there is no doubt that these tables will form a most important work of reference for anyone working on the history of the American economy. In addition to the topics mentioned, there are figures relating to the rural and urban population of each State, to the agricultural and non-agricultural labour force, the number of manufacturing establishments, total wage bill of employees, income per head in various categories and so on. The limitations of the basic data and the assumptions that have been made in constructing them are fully set out. The editors and authors must be congratulated on their industry and ingenuity, and the publishers on the technical excellence of the presentation.

\section{Collecting, Preserving and Studying Insects}

By Harold Oldroyd. Pp. $327+15$ plates. (London : Hutchinson and Co. (Publishers), Ltd., 1958.) 25s. net.

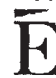
NTOMOLOGISTS need a work bringing together techniques of collecting and preserving insects, and this book will fully satisfy them. Collecting should not be an end in itself, but a means of getting to know insects, the first step towards studying their lives and activities. As the applied entomologist knows too well, our knowledge is still pitifully small, and it is to be hoped that this book will succeed in one of its objects, the stimulation of more voyages of discovery.

Its first chapter, "Where to Look", is followed by an account of the important business of first catching your insect, describing the various types of net, light traps and other devices, and there is a section on rearing and breeding. Methods of killing, temporary preservation, and preparation of permanent mounts are explained, together with the examination of specimens, the use and care of microscopes and the photography of live as well as dead insects.

There is a section on identification, a key to the orders of insects, and a general account of the features of each order with appropriate collecting and pre- servation methods. Also included are chapters on classification and nomenclature, the preparation of papers and illustrations for publication, with a guide to the specialist books and journals. Useful appendixes include a glossary of technical terms, reagents and formulæ and addresses of suppliers. A practical book, well illustrated, simply written and most readable, yet detailed enough to make a permanent work of reference, it will be invaluable alike to beginners and all entomology departments B. D. Moreton

Fruit and Vegetabie Preservation Industry in India (Proceedings of the Symposium held at the C.F.T.R.I., Mysore, on 4th and 5th October 1954.) Pp. xiv +485 . (Mysore: Central Food Technological Research Institute, 1956.) Rs. 6 ; 15s. ; 2.50 dollars.

I HIS book contains a foreword by the Director of the Institute, a list of participants in the symposium, the opening speeches and some 64 papers arranged in eleven sections (covering such varied subjects as raw materials, scientific aspects of preservation, quality control, microbiological problems, additives and preservatives, nutritive value, application of refrigeration, types of containers, plant and equipment, technical information services, ete.). It also reports the final discussion on need for action by the Government in promoting research, the type of research station required and the part the Govern. ment should play in establishing factories, together with the recommendations for fostering the industry submitted by the symposium to the Planning Commission and other Government departments.

Few, if any, of the papers contain any original data or observations but some are very useful summaries of existing knowledge. Taken altogether they provide a thorough survey of the state of the development of the fruit and vegetable preservation industry of India, and problems which will have to be faced in its further development.

R. G. Tomkins

\section{Physics for Science and Engineering}

By Robert L. Weber, Marsh W. White and Kenneth V. Manning. Pp. vii +617 . (London: McGrawHill Publishing Company, Ltd., 1957.) $60 s$.

TN this very sound introduction to physies, the first eighteen chapters (roughly one-third of the whole book) deal with the important background work of mechanics and the mechanical behaviour of materials, while about the same space is allotted to electricity and magnetism. The authors set out to train the reader in the methodical solution of problems, paying particular attention to units and significant figures, and set a good example in the many worked exercises in the text. Problems, indeed, make up a fair proportion of the short section on heat while that on light is quite lavishly descriptive, with some excellent pages on spectra, a chapter on colour which is spread with coloured figures in the text, and some good photographs illustrating polarization effects. Sufficient is said about electronics and nuclear physics for the reader to grasp clearly what these subjects are about; but the really thorough spadework has gone into the two major sections of the book, which will repay an equally thorough reading. Because of the emphasis on instruction rather than description, and the type of exercise given, it is possible to place the standard fairly accurately in terms of teaching in Britain. It is about that of the Advanced level of the General Certificate of Education.
G. R. NOAKES 